\title{
The rule of twin prime numbers are infinite \\ Mi \\ Zhou
}

\section{Zhoumi19920626@163.com}

Abstract:Whether there are infinitely twin prime numbers is an unsolved problem. In this paper,we use a simple and clear method to find the rule that the twi n prime numbers are infinitely.

Keywords: twin prime,number theory,infinitely

\section{Introduction:}

Whether there are infinitely many twin prime numbers is an unsolved problem. In this paper, we use a simple and clear method to find the rule that the twin prime numbers are infinitely. List the twin prime numbers in order: $\{5,7\},\{11,13\},\{17,19\},\{29,31\},\{41,43\},\{59,61\},\{71,73\}\{101,10$ $3\},\{107,109\},\{137,139\},\{149,151\},\{179,181\}$,

$\{191,193\},\{197,199\}, \quad \quad\{227,229\},\{239,241\},\{269,271\},\{281,283\},\{311,313\},\{347,349\}, \ldots \ldots$ add up each groups, then divided by 2 , get: $6,12,18,30,42,60,72,102,108,138$, 150 180 192 $198,228,240,270,282,312,348 \ldots \ldots$

Rule:

$18=6+12 \quad, \quad 30=12+18 \quad 42=30+12 \quad, \quad 60=42+18 \ldots \ldots$

Rule is :In this set of numbers, each number is add two numbers from the previous set, e.g. $198=$ $192+6,348=240+108$.

twin prime before 5000:

$\{5,7\},\{11,13\},\{17,19\},\{29,31\},\{41,43\},\{59,61\},\{71,73\}\{101,103\},\{107,109\},\{137,139\},\{149,151\}$, $\{179,181\},\{191,193\},\{197,199\},\{227,229\},\{239,241\},\{269,271\},\{281,283\},\{311,313\},\{347,349\},\{4$ $19,421\},\{431,433\},\{461,463\},\{521,523\},\{569,571\},\{599,601\},\{617,619\},\{641,643\},\{659,661\},\{809$, $811\},\{821,823\},\{827,829\},\{857,859\},\{881,883\},\{1019,1021\},\{1031,1033\},\{1049,1051\},\{1061,1063\}$, $\{1091,1093\},\{1151,1153\},\{1229,1231\},\{1277,1279\},\{1289,1291\},\{1301,1303\},\{1319,1321\},\{1427,14$ $29\},\{1451,1453\}, \quad\{1481,1483\},\{1487,1489\},\{1607,1609\},\{1619,1621\},\{1667,1669\},\{1697,1699\},\{1$ $721,1723\},\{1787,1789\},\{1871,1873\},\{1877,1879\},\{1931,1933\}, \quad\{1949,1951\},\{1997,1999\},\{2027,20$ $29\},\{2081,2083\},\{2087,2089\},\{2111,2113\},\{2129,2131\},\{2141,2143\},\{2237,2239\},\{2267,2269\},\{230$ $9,2311\},\{2339,2341\},\{2381,2383\},\{2549,2551\},\{2591,2593\},\{2657,2659\},\{2687,2689\},\{2711,2713\}$, $\{2729,2731\},\{2789,2791\},\{2801,2803\},\{2969,2971\},\{2999,3001\},\{3119,3121\}, \quad\{3167,3169\},\{3251$, $3253\},\{3257,3259\},\{3299,3301\},\{3329,3331\},\{3359,3361\},\{3371,3373\},\{3389,3391\}\{3461,3463\},\{34$ $67,3469\},\{3527,3529\},\{3539,3541\},\{3557,3559\},\{3581,3583\},\{3671,3673\},\{3767,3769\},\{3821,3823\}$, $\{3851,3853\},\{3917,3919\},\{3929,3931\},\{4001,4003\},\{4019,4021\},\{4049,4051\},\{4091,4093\},\{4127,41$ $29\},\{4157,4159\},\{4217,4219\},\{4229,4231\},\{4241,4243\}, \quad\{4259,4261\},\{4271,4273\},\{4337,4339\},\{4$ $421,4423\},\{4481,4483\},\{4517,4519\},\{4547,4549\},\{4637,4639\},\{4649,4651\}, \quad\{4721,4723\},\{4787,47$ $89\},\{4799,4801\},\{4931,4933\},\{4967,4969\}$,

get:

$6,12,18,30,42,60,72,102,108,138,150,180,192,198$, $228,240,270,282,312,348,420,432,462,522,570,600$, $618,642,660,810,822,828,858,882,1020,1032,1050$, 
1062, 1092, 1152, 1230, 1278, 1290, 1302, 1320, 1428, 1452, 1482, 1488, 1608, 1620, 1668, 1698, 1722, 1788, 1872, 1878, 1932, 1950, 1998, 2028, 2082, 2088, 2112, 2130, 2142, 2238 , 2268, 2310, 2340, 2382, 2550, 2592, 2658, 3300, 3330, 3360, 3372, 3390, 3462, 3468, 3528, 3540, 3558, 3582, 3672, 3768, 3822, 3852, 3918, 3930, , 4002, 4020, 4050, 4092, 4128, 4158, 4218, 4230, 4242, 4260, 4272, 4338, 4422, 4482, 4518, 4548, 4638, 4650, 4722, 4788, , 4800, 4932, 4968

Rule: In the array above, any number is the sum of the two numbers in the previous group

Validation:

$18=6+12,30=12+18,42=30+12,60=42+18,72=60+18,102=72+30,108=102+6,138=108+30,150=138+12,180=15$ $0+30,192=180+12,198=192+6$,

$228=198+30,240=228+12,270=240+30,282=270+12,312=282+30,348=240+108,420=312=108,432=420+12,46$ $2=432+30,522=462+60,570=462+108,600=570+300$,

$618=600+18,642=600+42,810=660+150,822=810+12,828=822+6,858=828+30,882=822+60,1020=828+192,10$ $32=1020+12,1050=1020+30,1062=1050+12,1092=1062+30$

$1152=1092+60,1230=1092+138,1278=228+1050,1290=1278+12,1302=1290+12,1320=1302+18,1428=1320+10$ $8,1452=1302+150,1482=1452+30,1488=1482+6$,

$1608=180+1428,1620=1608+12,1668=1608+60,1698=1668+30, \quad 1722=1620+102$,

$1788=1608+180,1872=1722+150,1878=1872+6,1932=1872+60,1950=1932+18,1998=1428+570,2028=1998+30$, $2082=1932+150,2088=2082+6,2112=2082+30,2130=2112+18,2142=2130+12,2238=2130+108,2268=2238+30$, $2310=2268+42,2340=2310+30$,

$2382=2340+42,2550=2310+240,2592=2550+42,2658=2550+108,3300=642+2658,3330=3300+30,3360=3330+3$ $0,3372=3360+12,3390=3372+18,3462=72+3390,3468=3462+6,3528=3468+60$,

$3540=3528+12,3558=3540+18,3582=3540+42,3672=282+3390 \quad \quad, \quad 3768=3672+6 \quad$, $3822=150+3672,3852=3822+30,3918=3768+150,3930=3918+12,4002=3930+72,4020=4002+18,4050=4020+30$, $4092=4050+42,4128=4020+108,4158=4128+30,4218=4158+60,4230=4218+12,4242=4230+12$, $4260=4242+18,4272=4260+12,4338=4230+108$,

$4422=4272+150,4482=4422+60,4518=180+4338,4548=4518+30$,

$4638=420+4218,4650=4638+12,4722=4650+72,4788=4722+60,4800=4788+12,4932=282+4650,4968=180+478$ 8

Verification results:no exception

Conclusion:Based on the rule,there are infinite number of twin primes So it's going to get bigger and bigger, and there's going to be an infinite number of tw in primes because it's going to get bigger and bigger!For every two sets of prime twin $s$, a third set of prime twins must be created, and the previous two set of prime twins, add them, will produce a new set of prime twins.And iterate! 